\title{
How I Think: Perspectives on Process, People, Politics, and Presence
}

\author{
William B. Ventres, $M D, M A$
}

The author, a seasoned midcareer family physician, summarizes his personal practice philosophy as it relates to encounters with patients. By focusing on 3 aspects of care-process issues, people issues, and political issues-he explores the unique characteristics of his clinical decision-making process. He concludes by noting that it is through examination of the question "How do I think in the work I do?" that family physicians can best bring their signature presences to their encounters with patients and their families. (J Am Board Fam Med 2012;25:930-936.)

Keywords: Culture, Family Medicine, Medical Education, Narrative, Philosophy, Primary Care

Over the past several years, 2 books have been published entitled How Doctors Think. One, by Harvard hematologist-oncologist Jerome Groopman, covers how medical subspecialists see and respond to their professional responsibilities. ${ }^{1}$ The other, by the medical humanities scholar Kathryn Montgomery, is an ethnographic review of hospital-based clinical decision-making by academic general internists. ${ }^{2}$ Reading these books inspired me to consider how I think as a seasoned family physician.

My current thinking clearly reflects my history. I trained in the mid-1980s at a residency program that was heavy on management of both in-hospital and ambulatory conditions but light on the process of clinical care. My schooling took place in block

This article was externally peer reviewed.

Submitted 3 April 2012; revised 5 July 2012; accepted 9 July 2012.

From the Master's Program in Public Health, School of Medicine, University of El Salvador, San Salvador, El Salvador; and the Department of Family Medicine, Oregon Health and Sciences University, Portland, OR.

Funding: Funding was received from the Fulbright Program of the US Department of State, Bureau of Educational and Cultural Affairs.

Conflict of interest: none declared.

Disclaimer: Neither the Fulbright Program nor the US Department of State had any role in the preparation, review, or approval of the article. The views expressed in this article are those of the authors and do not reflect those of the U.S. Department of State, the Institute of International Education, or the Fulbright Program.

Corresponding author: William B. Ventres, MD, MA, Programa de Maestría en Salud Pública, Universidad de El Salvador Facultad de Medicina, Edificio "La Rotonda," $2^{\text {nd }}$ o Piso, Final Calle Arce y 25 Avenida Sur, San Salvador, El Salvador (E-mail: wventres@gmail.com). rotations, all narrowly circumscribed by patients' ages or sex, location of care, and organ system subspecialty. I experienced the requisite continuity clinic experience and rotations in behavioral and community medicine as add-ons to the "real" work of clinical medicine.

After I had finished my residency, it took me approximately another 5 years to figure out what it meant to be a family physician. Two books that I encountered, Ian McWhinney's Introduction to Family Medicine and Gayle Stephens' The Intellectual Basis of Family Medicine, opened my eyes to how I might conceptualize my work. ${ }^{3,4}$ Then, in 1992, my colleague John Frey and I had the opportunity to gather a series of oral histories from many founders of the family medicine movement. I am deeply indebted to these people for their influence on my practice style. ${ }^{5}$ I am also grateful to the people who were my patients during that time, both for their help in my professional formation and for their patience.

I subsequently gained additional insight from several other writings. In his Textbook of Family Medicine, John Saultz proposed several factors to consider when approaching patient care, including access, continuity, comprehensiveness, coordination, and context. ${ }^{6}$ Other scholars have examined what family physicians actually do in practice-the proverbial "black box"-by focusing on issues ranging from the content of outpatient visits to the cognitive strategies that family physicians use to manage those visits. ${ }^{7,8}$ More recently, the study of 
complex systems-the science of investigating and describing both how the relationships between a system's parts influence its overall behavior and how the system in turn interacts with its environment- has been used to elucidate the varied considerations family physicians must consider when attending to their patients. ${ }^{9,10}$ The British practitioners Iona Heath and John Launer astutely reviewed the roles of family physicians as witnesses to the human experience and cocreators of personal narratives, respectively. ${ }^{11,12}$ In addition, I have found wisdom in family physician David Loxterkamp's many essays describing his rural practice in Maine. ${ }^{13-15}$

Although each of these works has helped me to conceptualize my work, there was something missing from them. They omitted some important aspects of how I think about patients and their presenting concerns. In this essay, I hope to fill in those missing areas.

I frame my personal practice philosophy around 3 sets of issues- of process, of people, and of politics-all within the context of the primary issue I face as a family physician: what to do at any given time with any $\geq 1$ patients who present to me with any $\geq 1$ problems.

\section{Process Issues}

As I see it, every patient encounter encompasses several needs: these include recognition, assessment, understanding, documentation, and communication. Each patient presents with a story that is formed by his or her personal experience of illness and the context of care (including, among other factors, the setting of care, the historical and relational dimensions of care, and such concerns as healthcare policy and economics). ${ }^{16}$ At a minimum, I listen to this story and conduct an examination. Simultaneously, I use my clinical knowledge, experience, and external resources to reorganize this information into an integrated clinical case that is amenable to the development of an assessment and plan. I also document and communicate this plan to my patient-a requisite part of any routine visit.

Five strategies help me manage this integration. First, I use a hypothesis model to assess presenting problems. I work from a clinical hypothesis using a combination of quantifiable information and clinical intuition born of learned experience to determine a working diagnosis. Knowing what is common and serious and what is not, keeping in mind the lessons of past mistakes, and attending to current realities (such as community patterns of disease and the unique characteristics of each patient), I balance the possibility that I might be wrong against the probability that I will be right. When a hypothesis needs revision, I expand the range of my thinking, step by step and visit by visit. This model works well for the kinds of undifferentiated problems with which many if not most patients present to every type of generalist practitioner.

When clinically stumped, I resort to assessing problems using the differential model that I learned in medical school. (Table 1.) As I review lists of diagnostic categories, Up-to-Date ${ }^{\circledR}$ and clinician colleagues are frequent companions, reminding me of possibilities beyond my immediate recollection. Yet, as professionally rewarding as it may be to uncover a clinical anomaly (think of all the attention paid to "zebras" in medical education), I do not ascribe to the school of diagnostic thinking whose highest goal is to discover a "plum of pathology."17 My expertise lies elsewhere.

Second, I use a "waterline" model for deciding on diagnostic and therapeutic strategies (Harrison R, Scherer J, Short RR. Waterline model. Kenmore, WA: Leadership Institute of Seattle; 2001; unpublished data; Figure 1). Knowing that time is often on my side in clinical practice-that many concerns are self-limited and that many others will make themselves known with time-I perform diagnostic testing only as I deem necessary at any given point in the process. A million dollar workup is not my first priority. Rather, my commitment is to continuing care: I go deeper below the waterline (ie, expand the scope of diagnostic testing and ther-

Table 1. Categories of Illness from a Differential Diagnosis Model

VINDICATE + P

Vascular
Inflammatory/infectious
Neoplastic
Degenerative
Intoxication/toxic
Congenital
Allergic/autoimmune
Traumatic
Endocrine/metabolic
Psychosomatic

Vascular

Inflammatory/infectious

Neoplastic

Degenerative

Intoxication/toxic

Congenital

Allergic/autoimmune

Traumatic

Psychosomatic 
Figure 1. Waterline Model of Diagnostic and Therapeutic Intervention (adapted from Harrison R, Scherer J, Short, RR. Waterline model. Kenmore, WA: Leadership Institute of Seattle; 2001; unpublished data).

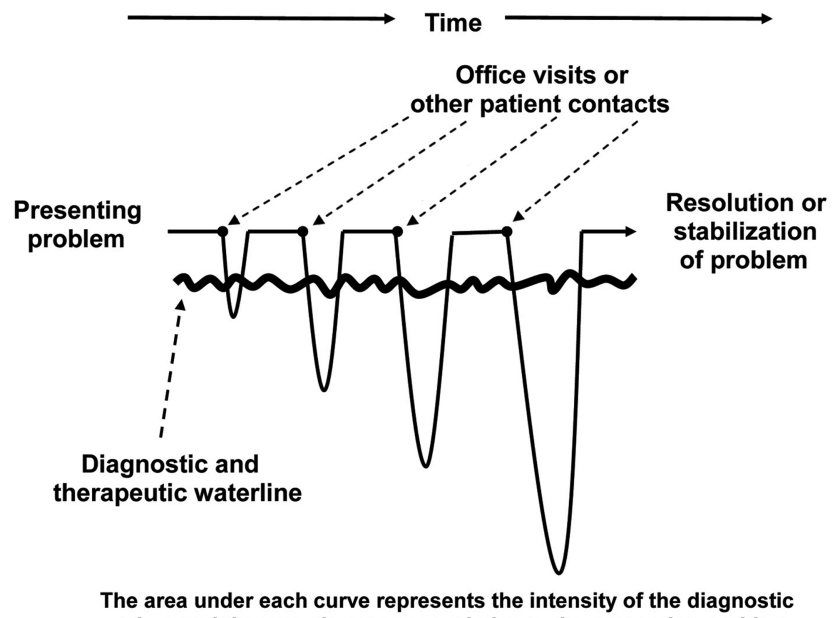

workup and therapeutic response relative to the presenting problem.

apeutic intervention) 1 step at a time and only as needed.

Third, I keep in touch with the special spot in my brain that helps me to identify and address urgent and emergent needs when they arise. This spot is a place to store details of conditions like testicular torsion and appendicitis that, although not especially common, do present in the ambulatory setting. I view keeping up to date with these conditions and their treatments as part and parcel of my work. I also cultivate the skill of retaining a calm and disciplined presence of mind when facing such problems.

Fourth, I focus on how I use time in each and every patient encounter. So often we focus on time only within the clinical encounter itself: how little of it we have, how we can manage it so as to adequately address patient concerns without falling behind in our schedules, and how we can use new information technologies to become more effective. Such issues are important: several authors have suggested valuable ways to approach office encounters efficiently without compromising patient-centered $^{\text {care. }}{ }^{18-20}$

The interval of time I am most concerned with, however, is that which takes place between office visits. This interval starts the moment my hand touches the examination room door handle as I get ready to leave. This is the instant many physicians fear most-the time when patients are prone to bring up their most pressing personal concerns. However, it is then, at the time of standing on the threshold, that I try to extend my presence with patients: I might recall some moment of importance in the visit, remind them of a key plan, or, very simply, let them know they have been heard and will continue to be heard. With most health concerns, especially chronic ones, the real work begins once the visit is over. (Consider, for example, the importance of patient adherence to taking a variety of medicines multiple times a day.) It is then that my role shifts; I become less a diagnostician and more an advisor and guide in absentia.

Fifth, as a family physician I choose from a repertoire of different thought patterns and responses based on who it is I am greeting in my office or at the hospital and what their presenting concerns may be. At certain times, systems theory, with its feedback loops and wide scope of consideration, is the most appropriate paradigm. At others, a narrowly defined, stepwise approach-first do $\mathrm{A}$, then $\mathrm{B}$, then $\mathrm{C}$-is better suited to the task at hand. Increasingly, too, I find that distributing and assigning tasks among office staff members (delegating work responsibilities to other members of the healthcare team) makes up an important part of my clinical decision-making. Developing routine standards for such tasks has become an exciting new role given the rapid implementation and institutionalization of nascent communication technologies. $^{21}$

\section{People Issues}

It is vital for me to remember that "good enough care," exemplified by adopting intent and follow-up 
as mantras for excellence, and by taking both practical and moral responsibility for the whole person (not, conveniently, for just 1 part of the patient or for just 1 intervention), most often outperforms the "best" care, especially when "best" is defined as an unrealistic goal of perfection. ${ }^{22}$ An orthopedic surgeon replacing the arthritic hip of an 82 year old may seek perfection in the procedure itself. A family physician recognizes that other factors will also influence this patient's outcomes and must be taken into account. For instance, the patient may have a cognitive inability to complete a postsurgical rehabilitation program; in that case, analgesic medications to reduce pain and improve function slightly, even with known side effects and lack of definitive "cure," might be a better option. Adopting a holistic approach to patient care has helped me to accept, examine, and learn from the normal nuances of patients' lives. My observation and belief that poor outcomes are caused not just by mistakes but by ordinary human variability has sustained me in the face of the emotional and intellectual rigors of sustaining a medical practice over a long time.

Revisiting my role in relation to the people I serve has also nourished my professional life. In any medical practice, there is always a dialectic between patient management and patient guidance, and I have come to think it unwise to assume that I can "manage" patients. Maybe I have some control in hospital settings-environments especially structured to maximize my ability to monitor and manipulate patients' body functions and minimize patients' ability to evade or deviate from my interventions. In ambulatory practice, however, I am forced to abdicate a position of being "in charge" the instant my patients exit the office.

Given this reality, it helps for me to assume a stance vis-à-vis patients of leader or guide. When I lead patients, I engage with them as partners. I am invested in their future, not simply telling them what to do. I encourage them by explicitly affirming their personal strengths and wisdom. I illuminate their potential by figuratively holding it in my awareness. By doing so openly, I invite patients to join me in creating a shared experience of trust, respect, and connection that is in itself therapeutic. Although I may use motivational interviewing techniques in this process, my best leadership goes well beyond these techniques. ${ }^{23}$

A major part of offering leadership is valuing patients' latent resiliencies in the face of suffering. The
Figure 2. Viktor Frankl's metaphor on "Why Believe in Others."

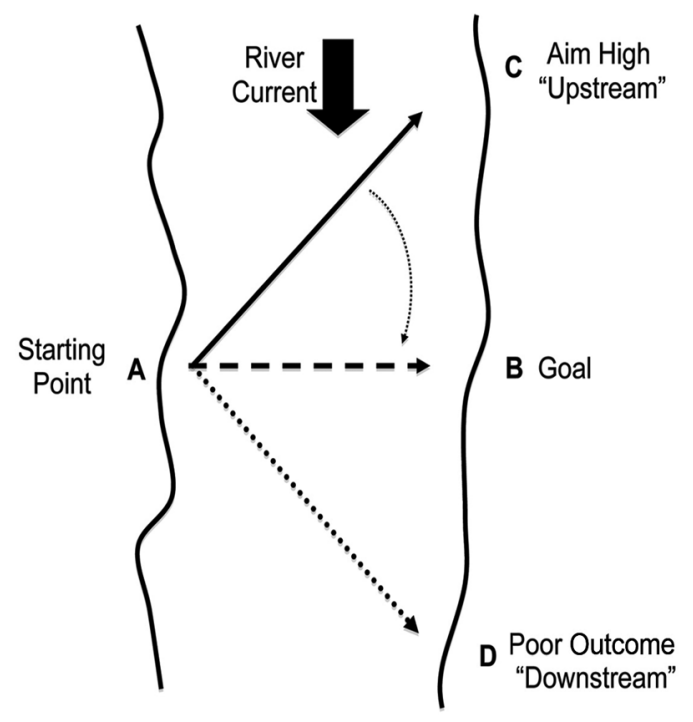

Austrian psychiatrist and Holocaust survivor Viktor Frankl talked about developing a vision for whom clients can become rather than seeing them just as who they are. ${ }^{24}$ He used the metaphor of swimming across a river beginning at point A (Figure 2). Due to the flow of the river, one needs to swim upstream (toward point C) to reach point B. It is the same with patients. Should I see them only in their present state, they are likely to end up "downstream" (at point D). Should I see them-despite their limitations-as worthy of high esteem and possessing the potential to improve their well-being through their own efforts, they are more likely to improve their health outcomes and endure episodes of illness with dignity and grace. As Henry David Thoreau noted in a similar vein, "Men hit only what they aim at. Therefore, ... they had better aim at something high." ${ }^{25}$ It is my job to help guide their aim.

\section{Political Issues}

In mentioning politics, I am not referring to Republicans or Democrats, or to healthcare policy, or to the question of whether, as family physicians in the United States, we work in anything resembling a medical "system." 26 Rather, I refer to how I negotiate power within my relationships with patients, families, and other practitioners given the culture in which we live and work.

Patients, to use the psychologist Donald Ransom's words, are not "dirty windows" through which we must peer in order view disease, the 
Table 2. Qualities and Skills in Physician-Patient Relationships

- Presence-An attentive and focused responsiveness to patients and their concerns. I am present when, irrespective of the time I have with patients, I demonstrate my interest in their well-being a people, rather than being distracted by chart or computer or even information I weigh while developing clinical assessments and plans.

- Touch-As a physician, the physical examination may aid in confirming clinical suspicions. For some patients, the contact of my hands on their bodies may be the only way they get appropriate physical contact all day or all month.

- Inquiry-The ability to convey interest in hearing what patients have to say in whatever way they know how to express it.

- Authenticity-The sincerity with which I approach patients not only as their personal physician, but also as my true self-another human being.

- Empathy-A feeling born of the knowledge that "we're all in the same boat" or that "I could be you." 28

- Words-The primary medium through which I communicate assessments and plans to patients, words can help or can harm. I hope I choose them with conscious intent, to maximize the clarity and emotional power they can convey.

"real" subject of medical practice. ${ }^{27}$ "Lifestyle choices" and "social determinants of health" are but 2 of many factors that contribute to patients' perceptions of their presenting problems and form a framework for how they intend to address them. Patients are not usually explicitly aware of these factors, and psychological and structural forces often limit their ability to make and follow through on their own decisions. It is of vital importance, I believe, to keep these factors and limitations in my awareness as I work.

Several qualities and skills mediate my awareness and my ability to elicit, hear, and understand patients' stories to help them gain confidence in my assessments and plans. These include presence, touch, inquiry, authenticity, empathy, and words (Table 2). They help me conceptualize how patients understand their illness experiences-often, as something vastly different from a disease process. They also help me to connect with my patients by seeing them as inhabitants of worlds that extend well beyond the confines of the office examination room or hospital suite.

That I cannot address all the medical or psychosocial needs of everybody does not bother me as it used to early on in practice. There are subspecialists to call on just as there are social workers and counselors, community health workers, and nurses and teachers and public health advocates. I no lon- ger feel embarrassed when I cannot remember the initial workup for patients whose diseases are unusual or whose conditions, although common, just do not respond to what I can offer as a first-lineof-care physician. Most days, year in and year out, I am able to help most people who come to my office. Even when I do not know the answers and choose to refer a patient, I am still able to help. Then I commonly become a trusted advisor, an interpreter of maladies 1 step removed from the exigencies of hands-on clinical care.

In the long run, it is very difficult to estimate with any accuracy the course that any patient's life will take in relation to his or her illness. As much as family medicine is a discipline of evidenced-based practices, it is also one respectful of individual differences. Any patient's future, however probable, is challenging to predict-and equally challenging to communicate in a meaningful way.

This uncertainty will always be part of the work I do. However, by reframing this uncertainty-by looking at it as a mystery to be explored with patients rather than a threat to be avoided-I have come to better terms with the unknown in medical practice. ${ }^{29}$ Such a view has helped me to understand the meanings that patients ascribe to their illnesses, whether they see them as natural deviations on life's path or as unexpected and unwanted bumps in the road. It has also helped me to come closer to elucidating and articulating my own work as a family physician.

\section{Concluding Philosophy}

As a family physician, I am not some kind of "super-poly-mini-subspecialist" using knowledge culled from the many subspecialty silos in which I was trained. Rather, I practice a synergistic integration of medicine and epidemiology and psychology and anthropology and theology. It is a studied practice that integrates general medical principles (applicable across divisions of time, age, sex, and place) with an understanding of patients within the context of family and community. Historically, there have been discussions about what the "family" in family medicine means; I take it as a metaphor for all that is not strictly biomedical, for all that can be seen using the insights gleaned from reflections on the human experience in the face of illness and infirmity. ${ }^{30-32}$

How I think as a family physician may be very different from how other family physicians think. I 
have observed colleagues at work, and their styles of practice suggest that some hold radically different views of either the patients and families to whom they attend or of their role relative to patient care. $^{33,34} \mathrm{I}$ also know that in their work with patients they have had clinical successes and failures, as I have. The fact that these differences exist and that they can coexist across a group practice as well as across an entire discipline is not my concern in writing this essay and outlining my thinking.

My concern is that too often we go through our days migrating from 1 examination room to another and relying on biomedical models of thought that exempt us from the work that is the core of our discipline: truly seeing patients as people, valuing them, recognizing the burdens they face, and then integrating these insights with our medical knowledge and experiential wisdom to form shared assessments and treatment plans with confidence and with compassion. I believe that continuously refocusing on this deep and touching work is, or should be, a critical part of our practice. ${ }^{35}$

To foster this process and help myself reflect on the values that guide my thinking and actions as a family physician, I have asked the question "How do I think in the work I do?" Examining this question (and its companion, "How do I feel about the work I do?") enables me to bring my most complete self-my authentic persona as a family physician and my passion for the profession - to my encounters with patients and their families. I believe that it can be so for all family physicians. Through this kind of self-examination-through questioning, reflection, and increased awareness-we could each cultivate our own signature presence. This would provide a place from which we could bring the best of who we are to every patient encounter and fully offer our unique gifts and talents. ${ }^{36}$ In this way we can touch the soul of our vocation, as each of us defines it, at the same time as also increasing our capacity to touch our patients' souls—and our own.

I thank Don Ransom, Mike Magill, and Jeff McAuliffe for their thoughtful comments on this article. I thank the faculty members at the LIOS Graduate College of Saybrook University for reminding me to value my signature presence. I also thank Deane DeFontes, my practice partner of several years at the Multnomah County Health Department, and my colleagues at the Oregon Health and Sciences University for graciously bringing to light many of the ideas presented in this article.

\section{References}

1. Groopman G. How doctors think. Boston (MA): Houghton Mifflin Harcourt; 2008.

2. Montgomery K. How doctors think. Oxford (UK): Oxford University Press; 2006.

3. McWhinney I. An introduction to family medicine. Oxford (UK): Oxford University Press; 1981.

4. Stephens GG. The intellectual basis of family medicine. Tucson (AZ): Winter Publishing; 1982.

5. American Academy of Family Physicians Foundation, Center for the History of Family Medicine. "Voices from Family Medicine" Project, 2011. Available at: www.aafpfoundation.org/online/foundation/ home/programs/center-history/oralhistory/voicesfm. html. Accessed June 15, 2012.

6. Saultz J. Textbook of family medicine. New York (NY): McGraw-Hill; 2000.

7. Stange KC, Zyzanski SJ, Jaén CR, Callahan EJ, Kelly RB, Gillanders WR, et al. Illuminating the 'black box': a description of 4454 patient visits to 138 family physicians. J Fam Pract 1998;46:377-89.

8. Christensen RC, Fetters MF, Green LA. Opening the black box: cognitive strategies in family practice. Ann Fam Med 2005;3:144-50.

9. Sturmberg J. Systems and complexity thinking in general practice-part 1: clinical application. Austral Fam Phys 2007;36:170-3.

10. Markham FW. A method for introducing the concepts of chaos theory to medical students. Theor Med Bioeth 1998;19:1-4.

11. Heath I. The mystery of general practice. London (UK): Nuffield Provincial Hospitals Trust; 1995.

12. Launer J. Narrative-based primary care: a practical guide. Oxford (UK): Radcliffe Medical Press; 2002.

13. Loxterkamp D. A vow of connectedness: views from the road to Beaver's farm. Fam Med 2001;33:244-7.

14. Loxterkamp D. Being there: on the place of the family physician. J Am Board Fam Pract 1991;4: 354-60.

15. Loxterkamp D. Doctors' work: eulogy for my vocation. Ann Fam Med 2009; 7:267-8.

16. Charon R. Narrative medicine: honoring the stories of illness. New York (NY): Oxford University Press; 2006.

17. Magraw R, Odegaard C, Ruhe CH, Fink D. Voices from family medicine: cooperation across disciplines. Interview by William B. Ventres, John J. Frey, and Alfred O. Berg. Fam Med 1992;24:618-22.

18. Mauksch LB, Dugdale DC, Dodson S, Epstein R. Relationship, communication, and efficiency in the medical encounter: creating a clinical model from a literature review. Arch Intern Med 2008;168:1387-95.

19. Epstein RM, Fiscella K, Lesser CS, Stange KC. Why the nation needs a policy push on patient-centered health care. Health Aff 2010;29:1489-95. 
20. Ventres W, Frankel R. Patient-centered care and electronic health records: it's still about the relationship. Fam Med 2010;42:364-6.

21. Ventres W, Kooienga S, Marlin R. EHRs in the exam room: tips on patient-centered care. Fam Pract Manag 2006;13:45-7.

22. DeGruy F. Mental health in the primary care setting. In: Donaldson MS, Yordy KD, Lohr KN, Vanselow NA, editors. Primary care: America's health in a new era. Washington (DC): The National Academies Press; 1996. p. 285-311.

23. Miller WR, Rollnick S. Motivational interviewing: preparing people to change. 2nd ed. New York (NY): Guilford Press; 2002.

24. Frankl V. Why believe in others. Presentation to the Toronto Youth Corps, 1972. Available at: www.ted. com/talks/viktor_frankl_youth_in_search_of_meaning. html. Accessed March 8, 2012.

25. Thoreau HD. Cramer JS, editors. Walden: a fully annotated edition. New Haven (CT): Yale University; 2004. p. 26.

26. Ferrer RL. Within the system of no-system. JAMA 2001;286:2513-4.

27. Ransom DC. Random notes: the patient is not a dirty window. Fam Syst Med 1984;2:230-3.
28. Spiro H, Peschel E, Curnen MGM, St James D. Empathy and the practice of medicine: beyond pills and the scalpel. New Haven (CT): Yale University Press; 2008.

29. Ventres W. The joy of family practice. Ann Fam Med 2012;10:264-8.

30. Carmichael LP, Carmichael JS. The relational model in family practice. Marriage Fam Rev 1982; 44:123-33.

31. Ransom DC, Vandervoort HE. The development of family medicine: Problematic trends. JAMA 1973; 225:1098-102.

32. Schmidt DD. The family as the unit of medical care. J Fam Pract 1978;7:303-13.

33. Ventres W, Nichter M, Reed R, Frankel R. Limitation of medical care: an ethnographic analysis. J Clin Ethics 1993;4:134-45.

34. Ventres W. Kooienga S, Marlin R, Vuckovic N, Stewart V. Clinician style and examination room computers: a video ethnography. Fam Med 2005;37: 276-81.

35. Schön DA. The reflective practitioner: how professionals think in action. New York (NY): Basic Books; 1983.

36. Burgess G. Dare to wear your soul on the outside: live your legacy now. San Francisco (CA): JosseyBass; 2008. 